\title{
Antiproliferative activity of an angular furanocoumarin-oroselol in human oral cancer cells is mediated via autophagy induction, inhibition of cell migration, invasion, and downregulation of PI3K/AKT signalling pathway
}

\author{
Yangyang Wang ${ }^{1}$, Rui Liu', Fanli Meng² and Zhejun Su² $₫$ \\ 'Department of Oral and Maxillofacial Surgery, Affiliated Hospital of Chengde Medical University, Chengde, Hebei Province, 067000, China; \\ 2Department of Stomatology, Affiliated Hospital of Chengde Medical University, Chengde, Hebei Province, 067000, China
}

Oral carcinoma is a lethal type of cancer associated with huge morbidity and mortality. Oral cancer patients show a very low survival chances even if diagnosed at early stages. The need for novel naturally occurring chemotherapeutic drugs increases due to high cost and toxicity of currently used clinical drugs. Present study was designed to investigate anticancer property of oroselol, keeping in view the medicinal potential showed by coumarin subclass furanocoumarins. MTT assay and clonogenic assays were implemented for viability assessments. Transmission electron microscopy was used for autophagic studies. The transwell chambers assay was used to investigate the migration and invasion. Western blotting was performed to determine the expressions levels of autophagy and $\mathrm{PI} 3 \mathrm{~K} / \mathrm{AKT}$ signalling related proteins. Results showed that oroselol could potentially inhibit viability of oral cancer SSC-4 cells in time- and dose-reliant fashion. The antiproliferative effects were mediated through autophagy induction as indicated by formation of autophagosomes and enhanced LC3-I expressions and reduced LC3-II and p62 expressions. Cancer cell migration and invasion was potentially supressed by oroselol cell treatment. The PI3K/AKT signalling pathway was blocked potentially by oroselol in SSC-4 cells which showed reduced phosphorylation of PI3K and AKT. In conclusion, oroselol holds a significant potential to induce autophagy-related antiproliferative effects along with inhibition of cell migration, cell invasion, and PI3K/AKT signalling pathway. Therefore, oroselol may prove to be a lead molecule in oral cancer chemotherapy provided further in vivo and toxicological studies are performed on it.

Keywords: Furanocoumarins, oral carcinoma, oroselol, autophagy, cell migration

Received: 23 May, 2021; revised: 27 June, 2021; accepted: 12 September, 2021; available on-line: 28 February, 2022

凶e-mail: 675508475@qq.com

Abbreviations: MTT, 3-[4,5-dimethylthiazol-2-yl]-2,5 diphenyl tetrazolium bromide; UV, Ultraviolet; DMSO, Dimethyl sulfoxide; PBS, Phosphate-buffered saline; BCA, Bicinchoninic acid; SDS-PAGE, sodium dodecyl sulfate-polyacrylamide gel electrophoresis; PVDF, Polyvinylidene fluoride or polyvinylidene difluoridee

\section{INTRODUCTION}

Oral carcinoma is a dangerous type of cancer malignancy located on lips or oral cavity (Barnes 2005). Oral cancer is associated with huge morbidity and mortality globally, with approximately $0.3 \mathrm{M}$ new cases and $0.15 \mathrm{M}$ deaths (Lingen et al., 2008). Traditionally, oral cancer because of its occurrence in dental area is defined as an oral squamous cell carcinoma, and out of all oral cancers histologically $90 \%$ arise from squamous cells (Warnakulasuriya, 2009; Vitale-Cross et al., 2009). It shows divergent levels towards propensity and differentiation for lymph node metastasis. The incidences of oral cancer remain almost three times higher in males than in females in the maximum ethnic groups (Dissanayaka et al., 2012). Cancers of pharynx and oral cavity are grouped collectively worldwide and ranks 6th among frequently prevailing cancers globally (van der Waal, 2009). It has been reported that about $90 \%$ of oral cancer cases potentially originate due to alcohol abuse and smoking, otherwise a preventable disease. A chain smoker and alcohol consumer have the highest chances for the development of oral cancer as these two risk factors pose synergistic effects (Lee et al., 2012; Warnakulasuriya 2011). Other risk factors include UV radiations and HPV (human papillomavirus) infection (initiates carcinogenesis in oropharynx) (Phillips et al., 2013; D’Costa et al., 1998). The presently availed treatment methodologies for oral cancer include radiation therapy, surgery, coadjutant therapy (therapy involving cisplatin, 5-fluorouracil, carboplatin, docetaxel, and paclitaxel) (Naidu et al., 2004; Stell \& Rawson, 1990). These treatments remain highly lethal due to side-effects and being high in cost. Thus, overcoming of these shortcomings of presently availed treatments requires novel therapeutic agents. Furanocoumarins are a rich subclass of chemical entities belonging to naturally occurring coumarin class of compounds mostly found in grapefruit (Piao, 2004). Furanocoumarins from grapefruit have been shown to exhibit numerous biological and medicinal importance including tumor inhibition, anti-inflammation, and antioxidant behaviour (Ho et al., 2001; Guo \& Yamazoe, 2004; Wang et al., 2006). These have also shown promising results in the promotion of bone health both in vivo and in vitro. Furanocoumarins interfere with different molecular pathways thereby potentially inhibiting the proliferation progression in different cancers (Kim et al., 2014). They modulate activator of transcription-3 and signalling transducer, expression of mitogen-stimulated protein kinase, phosphatidylinositol-3-kinase/AKT, and nuclear factor-kB (Hung et al., 2017; Hwang et al., 2010). Therefore, taking under consideration these biological activities, furanocoumarins possess remarkable anticancer potential. Oroselol molecule is an active constituent of Nardostachys jatamansi root oil and a member of furanocoumarins (Seshadri \& Sood, 1967). The parent plant of oroselol shows significant biological activity like an- 
tifungal, cardioprotective, and hepatoprotective (Purnima \& Kothiyal, 2015). Therefore, the current study was designed to explore the anticancer activity of oroselol molecule against oral cancer. Moreover, its effects on cellular autophagy, migration and invasion, and PI3K/AKT signalling pathway were also investigated.

\section{EXPERIMENTAL}

\section{Viability assay}

The effects of oroselol drug on oral cancer SSC-4 cell proliferation were assessed via MTT assay. In brief, SSC-4 cells were plated onto 96 -well plate at $37^{\circ} \mathrm{C}$ in $\mathrm{CO}_{2}(5 \%)$ incubator with each well carrying $1.5 \times 10^{4}$ cells. Then SSC-4 cells in each well were exposed to oroselol drug for $48 \mathrm{~h}$ and $72 \mathrm{~h}$ at variant doses viz 15, 30, 60 and $120 \mu \mathrm{M}$, controls were left untreated at normaxia. Consequently, treated cells were added with MTT stock solution ( $50 \mu \mathrm{L}$ with concentration $5 \mathrm{mg} / \mathrm{mL}$ ) for 20 minutes with incubation. $200 \mu \mathrm{L}$ of DMSO were used to dissolve then evolved formazan crystals. Finally, determination of optical density was performed with absorbance measurements at $570 \mathrm{~nm}$ with a microplate reader (OLYMPUS, Japan). The experiments for each concentration, including controls, were executed thrice.

\section{Colony formation assay}

To determine the impact of oroselol drug on colony formation of SSC-4 cells it was evaluated by clonogenic assay. The SSC-4 cells were loaded into 6-well plate with 200 cells per well and cultured for $48 \mathrm{~h}$ with variable doses of oroselol drug viz 15, 60 and $120 \mu \mathrm{M}$, and controls were left within oroselol deprived complete cultural medium. Cells were harvested at $80 \%$ confluence and then washed two times using PBS. Thereafter, oroselol treated SSC-4 cells were left untouched during an incubation for 10 consecutive days at $37^{\circ} \mathrm{C}$. Afterwards, SSC-4 cells were washed three times within PBS and then fixed in alcohol. Fixed cells were stained with crystal violet for visualization under a stereomicroscope (Carl Zeiss, Germany). Colonies bearing minimum of 50 cells were considered as significant for calculation.

\section{Transwell migration and invasion assay}

To monitor migration and invasion in SSC-4 cells, after being treated with oroselol drug, were investigated with transwell chambers assay. SSC-4 cells were transferred to upper transwell chambers post harvesting at a logarithmic phase of growth. The upper chambers contained cultural medium holding a 10\% fetal bovine serum and variant doses of oroselol drug viz 15, 60 and $120 \mu \mathrm{M}$ and controls were left at normaxia. Lower wells of the transwell chambers were filled with complete cultural media deprived of oroselol drug. After $48 \mathrm{~h}$ the non-migrated cells were rinsed with a cotton swab, and migrated cells were washed in PBS and fixed in ethanol. Thereafter, migrated cells were stained for visualization with crystal violet and numbered under a light microscope. Similar method was performed to evaluate the invasion of SSC-4 cells, except the walls of transwell chambers were coated with Matrigel.

\section{Western blotting}

To investigate the impact of oroselol molecules on $\mathrm{PI} 3 \mathrm{~K} / \mathrm{AKT}$ signalling in SSC-4 cells, western blotting

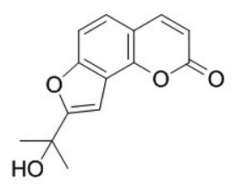

Figure 1. Chemical structure of oroselol molecule.

was implemented. After harvesting the SSC-4 cells at a logarithmic phase of growth, treatment with oroselol drug $(0-120 \mu \mathrm{M})$ was instigated with 24-well plates for $48 \mathrm{~h}$. Then cells were lysed in lysis buffer followed by protein content quantification with BCA assay within each lysate. Equal amounts of proteins were separated via SDS-PAGE then loaded over PVDF membranes through electrophoresis. These membranes were doped to eliminate non-specific binding using Tween $20 \mathrm{pH}$ of 7.5 ) and tris-buffer-saline holding $5 \%$ BSA, overnight. Thereafter, membranes were blotted with specific primary antibodies against LC3 I and II, p62, PI3K and AKT (1:1000 dilution) at $4^{\circ} \mathrm{C}$ for $12 \mathrm{~h}$ in the dark. Post primary antibody treatment, membranes were subjected to horseradish peroxidase conjugated secondary antibody (Cell Signalling Technology, MA, United States) for $1 \mathrm{~h}$ in the dark. Finally, visualization of the protein bands was performed using luminol reagent (Bio-Rad) by obeying manufacturer's guiding principle and chemiluminescence was investigated through Image Lab Software (Bio-Rad, Chem-doc).

\section{Statistical analysis}

All the experimental data collected by accomplishment of individual experiments in triplicates were subjected to regression and correlation analysis. Whole data was analysed by one-way ANOVA ( $p<0.05$, post hoc: tukey test) and represented as mean \pm S.D.

\section{RESULTS}

\section{Oroselol inhibits viability of oral cancer SSC-4 cells}

To assess the effects of oroselol (Fig. 1) on viability of oral cancer SSC-4 cells, MTT assay was performed after the treatment at various concentrations $(0-120 \mu \mathrm{M})$. It was observed that oroselol drug could potentially retard the proliferation in SSC-4 cells. Oroselol induced mild

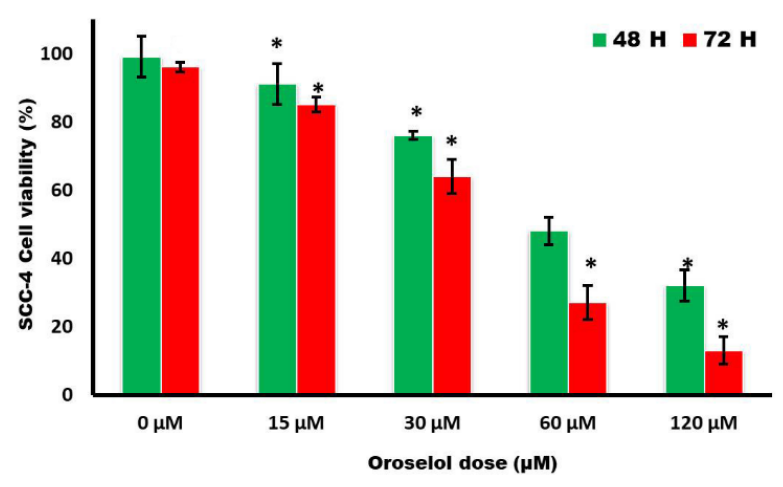

Figure 2. The oral cancer SSC-4 cells were subjected to MTT assay to determine the cellular viability after oroselol treatment at indicated doses.

Individual experiments were given three repetitions for each concentration and data was shown as mean \pm S.D. considering $p<0.02$ as a significant figure. 


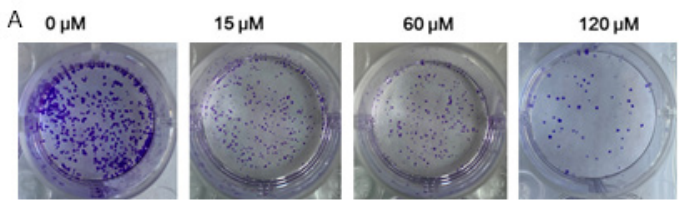

B

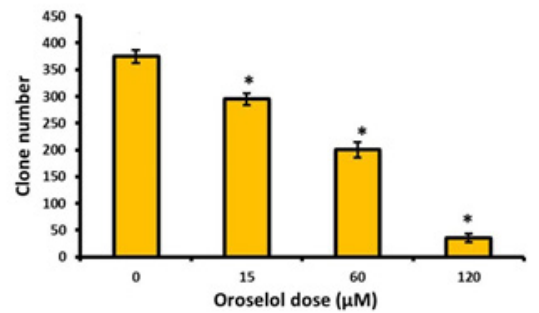

Figure 3. One title

(A) The SSC-4 cells were subjected to clonogenic analysis to determine the effects of oroselol on their colony generation. Cells were exposed for 10 days to indicated doses of oroselol drug and finally numbered under microscopy. (B) Graphical presentation of number of colonies generated after oroselol exposure of SSC-4 cells. Individual experiments were given three repetitions for each concentration and data was shown as mean \pm S.D. considering $p<0.02$ as a significant figure. Colonies with minimum number of 50 cells were considered for calculations.

anti-viability effects at low exposure time and significant results were observed after $72 \mathrm{~h}$ of treatment. Viability was supressed to almost $10 \%$ in comparison to controls (considered 100\% viable) after $72 \mathrm{~h}$ long treatment (Fig. 2). The study of SSC-4 colony formation was done via clonogenic assay and colonies were numbered after 10 days of treatment. Results showed that oroselol could possess remarkable anti-clonogenic activity against SSC-4 cells (Fig. 3A). The number of SSC-4 cell colonies were reduced to almost 20 at $120 \mu \mathrm{M}$ in comparison to controls, where the number stood at almost 370 (Fig. 3B).

\section{Anti-viability effects of oroselol on SSC-4 cells mediated via autophagic cell death}

It has also been reported that several furanocoumarins introduce their antiproliferative effects via stimulation of autophagy. Therefore, oroselol treated SSC-4 cells was further supported with western blotting at molecular levels. It indicated that the levels of activity of LC-I significantly augmented on application of oroselol in comparison to controls (Fig. 4A). Further, the levels of expressions of LC3-II and p62 decreased on enhancing oroselol doses. Thus, autophagy assessments indicated that anti-viability potency of oroselol drug in SSC-4 cells could potentially be due its autophagy induction.

\section{Oroselol inhibited invasion and migration in SSC-4 cells}

Furanocoumarins have been shown with great tendency to overcome cancer metastasis. Thus, in this study

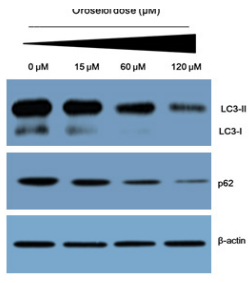

Figure 4. Western blotting showing the expression levels of autophagy allied proteins at indicated doses of oroselol in SSC-4 cells.

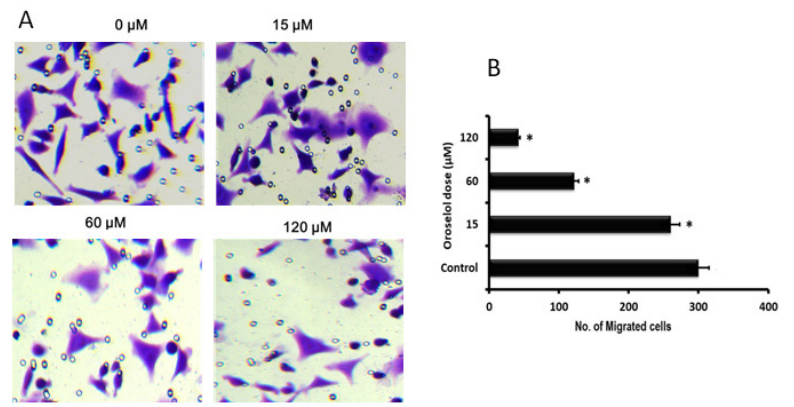

Figure 5. One title

(A) Transwell chambers migration assay. Results showing the decrease in migration of SSC-4 cells after exposure to oroselol drug at indicated doses. (B) Graphical representation of number of migrated cells after oroselol treatment of SSC-cells in transwell chambers. Individual experiments were given three repetitions for each concentration and data was shown as mean \pm S.D. considering $p<0.02$ as a significant figure.

oroselol was investigated for its anti-migration and antiinvasion capability of SSC-4 cells to inhibit metastasis in them. For that transwell migration and invasion assays were performed. SSC-4 cells were exposed to variant oroselol drug doses ranging from $0-120 \mu \mathrm{M}$ for $48 \mathrm{~h}$ and numbered under microscopy. Oroselol drug showed significant suppressive effects on migration of SSC-4 cells (Fig. 5A). The number of migrated SSC-4 cells declined to almost 40 in comparison to controls where migrated cell number stood at 300 (Fig. 5B). Likewise, oroselol could potentially inhibit invasiveness of SSC-4 cells as indicated in Fig. 6A. The number of invasive cells at $120 \mu \mathrm{M}$ of oroselol concentration was recorded to be nearly 60 in comparison to almost 380 at
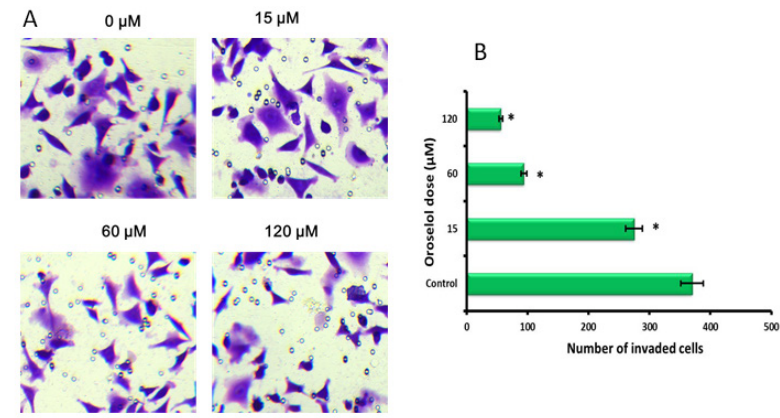

Figure 6. One title

(A) Transwell chambers invasion assay. Results showing the decrease in invasion of SSC-4 cells after exposure to oroselol drug at indicated doses. (B) Graphical representation of number of invasive cells after oroselol treatment of SSC-cells in transwell chambers. Individual experiments were given three repetitions for each concentration and data was shown as mean \pm S.D. considering $p<0.02$ as a significant figure.

the controls (Fig. 6B). Therefore, transwell migration and invasion analysis of oroselol treated SSC-4 cells showed that oroselol could inhibit metastasis in oral cancer.

\section{Oroselol blocked PI3K/AKT signalling pathway in SSC-4 cells}

The PI3K/AKT signalling pathway shows crucial role in activation of $\mathrm{m}$-TOR, which is an inhibitor of autophagy. Therefore, targeting this pathway leads to a smooth progression of autophagy. Western blotting showed that PI3K/AKT signalling pathway was potentially blocked by oroselol application in SSC-4 cells. The 


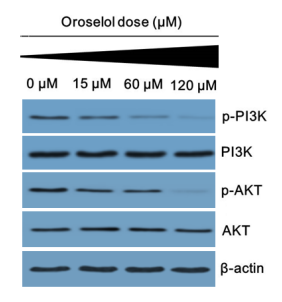

Figure 7. Western blotting results representing the activity of PISK/AKT signalling pathway allied phosphorylated and nonphosphorylated proteins.

SSC -4 cells were treated for $48 \mathrm{~h}$ with indicated oroselol doses.

levels of activity of phosphorylated PI3K and AKT declined remarkably in positive control groups than in negative controls. Moreover, the expressions of non-phosphorylated AKT and PIK remained almost the same all the time (Fig. 7).

\section{DISCUSSION}

Unfortunately, oral cancer treatment remains one of the major challenges for scientists and researchers. Alcohol consumption and smoking are the two main risk factors leading to oral cancer development, otherwise a preventable disease (Ko et al., 1995; Marshall et al., 1992). There is a pressing need for novel methodologies and chemopreventive drugs that can overcome the hazards of currently accessible management options. Therefore, the current study was undertaken to investigate oroselol furanocoumarin for its anticancer effects against oral cancer. Oroselol molecule's anticancer effects were searched for autophagy stimulation, migration inhibition, invasion inhibition, and targeting of $\mathrm{PI} 3 \mathrm{~K} / \mathrm{AKT}$ signalling pathway. Oroselol drug significantly targeted the proliferation progression in oral cancer SSC-4 cells. Moreover, the colony formation was also retarded by oroselol drug in a concentration dependent manner. Therefore, studies were carried out to unleash the mechanism beneath the antiproliferative effects of oroselol. Autophagy is one of the imperative defensive mechanisms in multicellular organisms and remains a potential target for chemopreventives (Mizushima 2007; Mathew et al., 2007; Hu et al., 2017). Autophagy is a mechanism in which impaired organelles, accumulated proteins and macromolecules are degenerated within autophagosomes (Lu et al., 2016). Autophagy is governed by a number of pro-autophagy and anti-autophagy proteins including LC3's, p62, and Beclin-1. Western blotting analysis indicated that oroselol could significantly target autophagy in oral cancer cells. Autophagy induction was recorded with enhanced LC3-I activity levels and reduced p62 and LC3-II activity levels. The migration and invasion in cancer cells cause metastatic disease which moves to distant places and proliferates (Kempen et al., 2008). Oroselol was investigated for effects on migration and invasion of SSC-4 cells through transwell chambers. It induced significant retardation of both migration and invasion and hence revealed potential as a significant anti-metastatic agent against oral cancer. Further, PI3K/AKT signalling pathway plays important role in autophagy inhibition (Heras-Sandoval et al., 2014; Zhai et al., 2014). PI3K/AKT is the upstream signalling pathway which stimulates $\mathrm{m}$-TOR and $\mathrm{m}$-TOR results in autophagy inhibition via modulation of transcription and translation of allied genes. Oroselol was examined for its effects on PI3K/AKT signalling pathway and showed remarkable potential of inhibition in $\mathrm{PI} 3 \mathrm{~K} / \mathrm{AKT}$ signalling pathway related proteins. The phosphorylation of $\mathrm{PI} 3 \mathrm{~K} / \mathrm{AKT}$ signalling pathway proteins remarkably declined in comparison to non-phosphorylated proteins whose activity levels remained almost intact.

\section{CONCLUSION}

Taking altogether, the results of this research indicate that oroselol furanocoumarin could potentially block the proliferation of oral carcinoma cells. These effects were mediated via stimulation of autophagy, migration and invasion inhibition and blockade of PI3K/AKT signalling pathway. Therefore, oroselol could supress the growth and proliferation of oral cancer and hence may prove a lead molecule in management of oral carcinoma.

\section{Conflict of interest}

The authors declare that there is no conflict of interest to report.

\section{REFERENCES}

Barnes L (2005) Organization WH and Cancer LAfRo. Pathology and genetics of head and neck tumours. World Health Organization

D'Costa J, Saranath D, Dedhia P, Sanghvi V, Mehta AR (1998) Detection of HPV-16 genome in human oral cancers and potentially malignant lesions from India. Oral Oncol 34: 413-420. https://doi. org/10.1016/S1368-8375(98)00028-1

Dissanayaka WL, Pitiyage G, Kumarasiri PV, Liyanage RL, Dias KD, Tilakaratne WM (2012) Clinical and histopathologic parameters in survival of oral squamous cell carcinoma. Oral Surg Oral Med Oral Pathol Oral Radiol 113: 518-525. https://doi.org/10.1016/j. oooo.2011.11.001

Guo LQ, Yamazoe Y (2004) Inhibition of cytochrome P450 by furanocoumarins in grapefruit juice and herbal medicines. Acta Pharmacol Sinica 25: 129-136

Heras-Sandoval D, Pérez-Rojas JM, Hernández-Damián J, PedrazaChaverri J (2014) The role of PI3K/AKT/mTOR pathway in the modulation of autophagy and the clearance of protein aggregates in neurodegeneration. Cellular Signall 26: 2694-2701. https://doi. org/10.1016/j.cellsig.2014.08.019

Ho PC, Saville DJ, Wanwimolruk S (2001) Inhibition of human CYP3A4 activity by grapefruit flavonoids, furanocoumarins and related compounds. I Pharm Pharm Sci 4: 217-227

Hung WL, Suh JH, Wang Y (2017) Chemistry and health effects of furanocoumarins in grapefruit. J Food Drug Anal 25: 71-83. https:// doi.org/10.1016/j.jfda.2016.11.008

Hwang YP, Yun HJ, Choi JH, Kang KW, Jeong HG (2010) Suppression of phorbol-12-myristate-13-acetate-induced tumor cell invasion by bergamottin via the inhibition of protein kinase $\mathrm{C} \delta / \mathrm{p} 38$ mitogen-activated protein kinase and $\mathrm{JNK} /$ nuclear factor- $x \mathrm{~B}$-dependent matrix metalloproteinase-9 expression. Mol Nutrit Food Res 54: 977990. https://doi.org/10.1002/mnfr.200900283

Kempen I, Hemmer M, Counerotte S, Pochet L, De Tullio P, Foidart JM, Blacher S, Noël A, Frankenne F, Pirotte B (2008) 6-Substituted 2-oxo-2H-1-benzopyran-3-carboxylic acid derivatives in a new approach of the treatment of cancer cell invasion and metastasis. Eur J Med Chem 43: 2735-2750. https://doi.org/10.1016/j.ejmech.2008.01.024

Kim SM, Lee JH, Sethi G, Kim C, Baek SH, Nam D, Chung WS, Kim SH, Shim BS, Ahn KS (2014) Bergamottin, a natural furanocoumarin obtained from grapefruit juice induces chemosensitization and apoptosis through the inhibition of STAT3 signaling pathway in tumor cells. Cancer Lett 354: 153-163. https://doi.org/10.1016/j. canlet.2014.08.002

Ko YC, Huang YL, Lee CH, Chen MJ, Lin LM, Tsai CC (1995) Betel quid chewing, cigarette smoking and alcohol consumption related to oral cancer in Taiwan. J Oral Pathol Med 24: 450-453. https://doi. org/10.1111/j.1600-0714.1995.tb01132.x

Lee J, Taneja V, Vassallo R (2012) Cigarette smoking and inflammation: cellular and molecular mechanisms. J Dent Res 91: 142-149. https://doi.org/10.1177/0022034511421200

Lingen MW, Kalmar JR, Karrison T, Speight PM (2008) Critical evaluation of diagnostic aids for the detection of oral cancer. Oral Oncol 44: 10-22. https://doi.org/10.1016/j.oraloncology.2007.06.011

Lu XY, Wang ZC, Ren SZ, Shen FQ, Man RJ, Zhu HL (2016) Coumarin sulfonamides derivatives as potent and selective COX-2 inhibitors with efficacy in suppressing cancer proliferation and metas- 
tasis. Bioorg Med Chem Lett 26: 3491-3498. https:/ / doi.org/10.1016/j. bmcl.2016.06.037

Marshall JR, Graham S, Haughey BP, Shedd D, O'Shea R, Brasure J, Wilkinson GS, West D (1992) Smoking, alcohol, dentition and diet in the epidemiology of oral cancer. Eur I Cancer Part B: Oral Oncol 28: 9-15. https://doi.org/10.1016/0964-1955(92)90005-L

Mathew R, Karantza-Wadsworth V, White E (2007) Role of autophagy in cancer. Nat Rev Cancer 7: 961-967. https://doi.org/10.1038/ nrc 2254

Mizushima N (2007) Autophagy: process and function. Genes Develop 21: 2861-2873. https://doi.org/10.1101/gad.1599207

Naidu MU, Ramana GV, Rani PU, Mohan IK, Suman A, Roy P (2004) Chemotherapy-induced and/or radiation therapy-induced oral mucositis - complicating the treatment of cancer. Neoplasia 6: 423. https://doi.org/10.1593/neo.04169

Phillips J, Moore-Medlin T, Sonavane K, Ekshyyan O, McLarty J, Nathan CA (2013) Curcumin inhibits UV radiation-induced skin cancer in SKH-1 mice. Otolaryngol - Head, Neck Surg 148: 797-803. https:// doi.org/10.1177/0194599813476845

Piao XL, Park IH, Baek SH, Kim HY, Park MK, Park JH (2004) Antioxidative activity of furanocoumarins isolated from Angelicae dahuricae. J Ethnopharmacol 93: 243-246. https://doi.org/10.1016/j. jep.2004.03.054

Purnima BM, Kothiyal P (2015) A review article on phytochemistry and pharmacological profiles of Nardostachys jatamansi DC-medicinal herb. J Pharmacogn Phytochem 3: 102-106

Seshadri TR, Sood MS (1967) Chemical comparison of the roots of Selinum vaginatum and Nardostachys jatamansi. Phytochemistry 6: 445-446. https://doi.org/10.1016/S0031-9422(00)86305-0

Stell PM, Rawson NS (1990) Adjuvant chemotherapy in head and neck cancer. Brit J Cancer 61: 779-787. https://doi.org/10.1038/ bjc.1990.175 van der Waal I (2009) Potentially malignant disorders of the oral and oropharyngeal mucosa; terminology, classification and present concepts of management. Oral Oncol 45: 317-323. https://doi. org/10.1016/j.oraloncology.2008.05.016

Vitale-Cross L, Czerninski R, Amornphimoltham P, Patel V, Molinolo AA and Gutkind JS (2006) Chemical carcinogenesis models for evaluating molecular-targeted prevention and treatment of oral cancer. Cancer Prev Res (Phila) 2: 419-422. https://doi.org/10.1158/19406207.CAPR-09-0058

Wang X, Nakagawa-Goto K, Kozuka M, Tokuda H, Nishino H, Lee KH (2006) Cancer preventive agents. Part 6: Chemopreventive potential of furanocoumarins and related compounds. Pharm Biol 44: 116-120. https://doi.org/10.1080/13880200600592178

Warnakulasuriya S (2009) Global epidemiology of oral and oropharyngeal cancer. Oral Oncol 45: 309-316. https://doi.org/10.1016/j.oraloncology.2008.06.002

Warnakulasuriya S (2011) Waterpipe smoking, oral cancer and other oral health effects. Evidence-based Dentistry 12: 44-45. https://doi. org/10.1038/sj.ebd.6400790

Xu H, Laraia L, Schneider L, Louven K, Strohmann C, Antonchick AP, Waldmann H (2017) Highly enantioselective catalytic vinylogous propargylation of coumarins yields a class of autophagy inhibitors. Angewandte Chemie Int Edn 56: 11232-11236. https://doi. org/10.1002/anie.201706005

Zhai C, Cheng J, Mujahid H, Wang H, Kong J, Yin Y, Li J, Zhang $\mathrm{Y}$, Ji X, Chen W (2014) Selective inhibition of PI3K/Akt/mTOR signaling pathway regulates autophagy of macrophage and vulnerability of atherosclerotic plaque. PloS One 9: e90563. https://doi. org/10.1371/journal.pone.0090563 